\title{
Priming as a Process and as a Function in Agenda Setting*
}

\author{
Gennadiy Chernov \\ Correspondence: Gennadiy Chernov, School of Journalism, Ad Hum Bldg 105 University of Regina Regina, SK, S4S \\ 0A2, Canada. Email: gennadiy.chernov@ uregina.ca
}

Received: June 14, 2017

doi:10.11114/smc.v6i1.3205
Accepted: March 23, 2018

Online Published: April 12, 2018

URL: https://doi.org/10.11114/smc.v6i1.3205

\begin{abstract}
This paper explores the priming mechanism in agenda setting in conjunction with information processing and other variables such as relevance and mental models. Over the years, certain confusion started to accumulate about what is a place of priming in the media effects realm in general and in agenda setting in particular. Moreover, new advances in the psychology studies of priming and in media priming were not accounted for in agenda setting. The paper aims at a) reviewing what developments in the field have taken place over the years, and b) revisiting and clarifying priming in its specific application to public agenda setting based on the new developments.

The paper concludes with a new working definition of priming and describes a more complex theoretical framework of priming that shows how mental models and relevance explain priming effects better than accessibility only in deliberative information processes, and that even in more automatic, peripheral processing, accessibility plays a role as only an initial trigger for further issue or performance evaluations.
\end{abstract}

Keywords: agenda setting, priming, media priming, mental representations, accessibility

\section{Introduction}

Priming is an important concept in psychology (Higgins, 2014), but it also won a special status in mass communication and political communication research. In general form, 'priming refers to the effect of some preceding stimulus or event on how we react, broadly defined, to some subsequent event or person'. (Roskos-Ewoldsen \& Roskos-Ewoldsen, p.174, 2009)

In mass communication it is possible to distinguish two lines of research related to priming:

First, media priming has become a separate, independent area of research (Appel, 2011; Arendt, 2015; Roskos-Ewoldsen, Roskos-Ewoldsen, \& Carpentier, 2009). Second, agenda setting theory treats priming as its extension (McCombs, 2013). For example, Blumler (2015) cites it as "an adjunct of agenda setting" (p. 427) and includes it into the list of three dominant media effects theories alongside framing and agenda setting.

Over the years, certain confusion started to accumulate about what is a place of priming in media effects realm in general and in agenda setting in particular; whether priming is a theory or an effect, and how it is precisely defined. Some scholars (Price, \& Tewksbury, 1997; Scheufele \& Tewksbury, 2007) reduce priming to increased accessibility. Others (Ottati, Wilson, Lambert, 2016) consider framing effects to be a form of priming. Sometimes a doubt is expressed about whether priming is a theory or just an effect of other processes:

“...a series of studies designed to demonstrate that priming or framing effects can be induced under a certain set of conditions or within a specific context may be portrayed as evidence for "priming theory" or "framing theory" when in fact, the studies themselves have only demonstrated that the priming or framing effects have occurred." (Berger, Roloff \& Roskos-Ewoldsen, 2010, p. 8).

Mass communication researchers borrowed the term from social cognitive psychology and media effects literature adapted it in a way that applies to mass media environment. Many of them cite the most popular definition stating that "priming refers to changes in the standards that people use to make political evaluations" (Iyengar \& Kinder, 1987, p. 63). This definition has its own merits. However, the processes leading to change were not spelled out precisely. Moreover, the standards used for evaluations were offered in mostly descriptive terms without serious theoretical

\footnotetext{
*This publication is in part supported by the President's Publication Fund, University of Regina.
} 
considerations. Two things happened over the years:

1) Priming studies in psychology have evolved further and encompassed a deeper understanding of priming than in time when the cited definition was coined, and 2) there was a lack of effort to revisit the concept of priming as a theory to better explicate its relationships with other media effects theories. The definitional and conceptual confusion in the way priming is addressed in the media effects literature hampers further progress as manifested by the inconclusive debate between agenda setting and framing scholars (Ghanem, 1997; Scheufele, \& Tewksbury, 2007; Ghanem, McCombs, \& Chernov, 2009; Cacciatore, Scheufele, \& Iyengar, 2016). While previous studies found additional manifestations of priming effects as the result of media use ( Carpentier, 2014; Kim, Han, Choi, \& Kim, 2012; Lee, 2010), they consider priming as a result of accessibility or perceived importance, but do not theorize about it as a self-contained theoretical concept having clear procedural borders between triggering media primes and subsequent evaluations. Psychology and media priming studies have evolved beyond accessibility and included judged usability (Higgins, 2014) and mental representations (Roskos-Ewoldsen, 2009).

The priming process may include more complex components than a straightforward automatic memory activation (Molden, 2014). There is a broad range of priming explications from purely evaluative construal (Bargh, 2006), to the changing standards media set for such evaluations (Brewer, Graf \& Willnat, 2003)

The purpose of this paper is a) to demonstrate what recent developments in studying priming in psychology and media may be of relevance for priming theory in media effects; b) to clarify the priming definitional and conceptual confusion existing in the current media effects literature, and c) to offer a model that clearly describes priming processes and functions in light of reconsidering recent theoretical developments in priming.

When a concept is borrowed from other disciplines, there is a concern that this transfer may be mechanistic. Additional theorizing is needed to apply such a concept to the existing conceptual framework in the new discipline. The novelty and importance of this paper is that it gaps the current difference of conceptualizing priming in psychology and media effects literature, specifically in agenda setting. Understanding media priming requires clarity of its definitional aspects, including the explication of psychological bases of priming and how they apply to agenda setting.

\section{Priming: Conceptual Issues and Psychological Bases}

Nearly all definitions of priming include an idea of presenting a certain stimulus that triggers a certain construct making it available for evaluating something other than the construct itself. As Molden (2014) put it: “... it is now virtually axiomatic among social psychologists that the mere exposure to socially relevant stimuli can facilitate, or prime, a host of impressions, judgments, goals, and actions, often even outside of people's intention or awareness" (p.2). Priming has been evolving in the direction of a greater conceptual complexity and a more distinct elaboration on the difference of the concept as a process and as an effect.

Priming is more complex than a direct stimulus-reaction model may suggest. It involves cognitive structures as mediators, and it is less deliberate than a reasoning process of making arguments and consciously evaluating various social phenomena.

An initial understanding of priming in cognitive psychology didn't account for the increased complexity of mediating factors and underlying mechanisms of social and media priming. The key concept that refers to priming is accessibility. Accessibility facilitates knowledge activation from memory (Forster \& Lieberman, 2007). Higgins (1996) also emphasized the accessibility importance for priming. However, he has recently given equal treatment to three psychological elements - accessibility, applicability and the judged usability as "...the final stage of actually using the activated representation to do something (e.g., categorization). (Higgins \& Eitman, 2014, p.237) The authors do not separate the activation process from what they activate - representations. This new, more nuanced vision not only adds an important characteristic of priming, but it also seems to emphasize the importance of the judged usability. The latter determines the impact of priming on what follows it: the activated representations trigger the subsequent categorization of primed information. A more general picture of what is going on emerges: stimuli are presented and they activate related and/or broader representations leading to more deliberate processes of categorization and/or evaluation. Moreover, for priming to work, motivational forces have to be engaged as well. Higgins and Eitman (2014) suggested "...that whether a stimulated representation in memory is activated (or its information becomes accessible) depends on its motivational relevance (p240). Both relevance and judged usability cannot be accounted by accessibility only.

Forster and Lieberman (2007) treat judged usability as a cognitive process and describe it as "...the perceived appropriateness of applying some knowledge to a stimulus (p.203)

The fact that mental representations with their obviously more complex and less automatic nature have found more coverage in priming literature shows further theoretical steps ahead in understanding the phenomenon. Judgment-relevant knowledge organized in memory in a certain manner and retrieved as an activated part of the 
representation of this knowledge. Activating accessible nodes in memory allows for retrieving broader mental representations to which these nodes belong. Wyer (2007) distinguishes between parallel and sequential retrievals. The former is more deliberative and goal-oriented, the latter is more spontaneous. The importance of this distinction comes from determining the boundaries of priming, in understanding, for example, where priming ends and judgment starts. Wyer also considers spontaneous inferences as part of the later retrieved representations. He also seems to locate priming in the realm of transient, situational presentations that allow for easy accessibility, and generalized presentations are used when more deliberate comprehension processes kick in. This distinction allows us to determine when mental representations go beyond priming.

Aside from mental representations and judged usability, the notion of a standard is also important for priming studies in psychology and media effects. Psychologically, a standard is defined as "... a criterion or rule established by experience, desires, or authority for the measure of quantity and extent, or quality and value" (Higgins, 1990, p.302). Some scholars tie the information about standards to evaluations (Markman \& Mullen, 2003). Evaluations per se are not considered a part of priming, but standards are - as conceptual clues (Biernat \& Eidelman, 2007). The role of standards in priming will be further clarified at the media effects level.

The key conceptual difficulty which has emerged and persisted in different areas of priming lies in understanding priming both as a process and an effect. In psychological terms, priming is not understood as, for example, information processing. The noun "prime" stands for a trigger of the process, and its result is mostly named "an effect". The word "effects" is instrumental for the following definition: "priming has generally referred to facilitative effects of some event or action on subsequent associated responses" (Molden, 2014, p.3) However, certain effects are said to be the effects of priming as if priming is a process or a mechanism (Bargh, 2013). It seems that priming as a mechanism or a process equates to two components: "(1) the "excitation" of representations in memory by some process of spreading activation through a semantic network of associations, and (2) the use of these excited, or accessible, representations to encode information about a social target that was subsequently received." (Molden, 2014, p.6). But as it was shown already, priming involves more than excitation and accessibility, complemented by making associations and spontaneous inferences about some elements of mental representations and standards. All these developments of priming studies were not necessarily accounted for by media effects research in the areas where priming was borrowed and applied.

\section{Media Priming}

As it was mentioned, priming is also widely implicated in the media effects studies. Its specific version is often called media priming, and broadly applied in the areas of media induced violence, stereotyping through media content, and so on. Over the years, media priming has also been evolving towards clarifying its definitional and conceptual aspects; media priming has embraced mental representations as its cognitive component (Roskos-Ewoldsen \& Roskos-Ewoldsen, 2009); certain inroads into the dose dependency concept have been made (Arendt, 2015); the efforts have been made to clarify media priming as a process (Lang \& Roskos-Ewoldsen, 2010) There is no shortage of definitions of media priming in media effects literature. It hampers shared conceptual understanding. Roskos-Ewoldsen, Roskos-Ewoldsen, and Carpentier (2009), offered a broad one: "Media priming refers to the short-term impact of exposure to the media on the subsequent judgments or behaviors". (p.74) It includes "behaviors" and such an inclusion is not generally warranted by all researches. Appel (2011) also keeps the notion of "behavior", but concentrates more on the unintended effects: "Media priming refers to the residual, often unintended consequences of media exposure on subsequent perceptions, judgments, and behavior (Appel, 2011). The unintentional character of priming seems to have more important theoretical consequences as it allows to distinguish priming from other effects, often intended (like framing, for example). As Potter (2014) puts it, “... given the characteristics of the media literature, there is a danger of great variation in definitions" (p.108).

A deeper look at media priming as a process revealed that there is insufficient evidence that priming is underlined by memory node activation only. In fact, as Roskos-Ewoldson \& Roskos-Ewoldsen (2009) suggest, the automatic memory network models of media priming lack an explanatory power of the phenomenon. More dynamic and deliberative mental models not only complement accessibility mechanisms, but also better account for the complexity of the processes involved in media priming. Deliberate information processing definitely cannot rely only on the accessibility of issues, but even using less conscious, more peripheral route of information processing does not imply that some conscious cognitive effort is excluded from the process (Miller, 2007; Carpentier, 2014).

The enrichment of procedural aspects has come in part from a complex picture of mental representations in media priming.

The limited explanations of media priming do not take into account a broader context of media landscape. Accessibility models often deal with a single message exposure, a construct triggered by this exposure and an evaluation made on the 
basis of the former two. In real life, exposure takes place in a broader array of related messages, and evaluations become a result of multiple factors as outcomes of complex mental representations. Individuals construct a mental model of what happens and this model is not static, but a flexible entity (Johnson-Laird, 1989). Studies in priming usually isolate perception of a primed construct from its context and that is why researchers have various results at times. Unaccounted context may vary from study to study and slips under the radars of even rigorous experimentation (Garnham, \& Oakhill, 2013).

Mental models are mental representations, but studied not only as qualities, but dynamic mechanisms (Roskos-Ewoldsen, D., Roskos-Ewoldsen \& Carpentier, 2009). In a more static view of mental representations, they are classified as a dichotomy of picture-like vs. language-like representations ( Paivio, 1986), or whether mental representations have independent content from what they represent in the environment (Jackobson, 2013). The understanding of mental representations has not changed much since the classic text of Paivio (1986). The outside world is presented in words and images in our heads and these presentations can be retrieved, reflected and manipulated. These manipulations determine the number of elements and their relations in a representation. In general, “... it is difficult to distinguish representational structure from representational function or process." (Paivio, 1986, p. 20). However, with each new way of manipulating representations, the latter change. They are not static. The dynamic view of representations as mental models claims to implicate representations in information processing, making judgments and formulating inferences (Roskos-Ewoldsen, D., Roskos-Ewoldsen \& Carpentier, 2009). In such a view, media priming becomes a connecting mechanism that ties media messages to deliberative cognitive processes triggered by media. The temporal and stimulus-oriented aspects of early definitions are only the entry points to a deeper exploration of the media priming that tries to overcome a simplistic 'accessibility' model. The effort is made to show that “... traditional psychological explanations of priming (i.e., priming within network models of memory) has limited our progress towards understanding of media priming. Instead, we suggest that a focus on how people comprehend media messages and resulting mental representations provides a better explanation for media priming " (Roskos-Ewoldsen and Roskos-Ewoldsen , p.74).

Another issue related to media priming is the problem of reverse causality (Hart and Middleton, 2014). The idea is that a change in the standards and direction of evaluations may be triggered not by news stories, but by prior predispositions to an issue. Lenz $(2009,2012)$ put forward a projection hypothesis, an alternative explanation that individuals exposed to the media reflect their prior stance in their issue evaluations, not issue salience highlighted by the media. Democratic electoral processes play an important part in some studies of priming, that is why the word 'voters' is used in the following explication of the priming vs. projection controversy:

"The priming hypothesis implies that the media have the capacity, via issue coverage, to shift the terms of presidential support. If projection holds, however, voters are unresponsive to changing news coverage. They simply interpret new information so as to remain consistent with prior beliefs. Priming, therefore, ascribes to the media a significant role in politics while projection does not.» (Hart \& Middlton, 2014, p.582)

If this alternative explanation holds the robustness of the media priming findings could be questioned. There is no empirical confirmation of this explanation so far (Lenz, 2012; Hart \& Middlton, 2014). However, if any theory does not develop further and ceases to explain new relevant empirical data, a search for alternatives will intensify.

The concept of dose, or frequency with which priming occurs as well as its implications, has gained more attention recently. Miller and Krosnick (2000) defined dose as “the amount of media coverage on an issue that enters a person's short-term or working memory" (p. 83). This approach raised the question whether priming effects are linear. If they are not, some researchers argue, we may overlook these effects under certain conditions Arendt (2015) found that at some high dose level the priming effects decayed. In other words, there is not only a threshold that media exposure has to overcome to trigger priming, but also there is a threshold beyond which no additional exposure can lead to priming effects. These findings can also be helpful in understanding priming effects in agenda setting.

\section{Agenda Setting and Priming}

Previous sections demonstrated how priming in psychology and media priming have evolved and modified, and how greater definitional and conceptual clarity has been sought and partly achieved. Agenda setting, a theory that includes priming as its indispensable part, has not always accounted for these changes. Among theories that deal with such judgments agenda setting dominates as a well-established and empirically confirmed phenomenon that connects media exposure with audience's subsequent judgments (McCombs, 2013). Scholars related agenda setting and priming starting from the first experimental studies in agenda setting ((Iyengar \& Kinder, 1987). Sometimes priming is called an extended function of agenda setting effects (McCombs, 2004). There is a debate about how agenda setting is related to priming and framing. Among these three, only agenda setting has emerged as a theory in the mass communication realm while priming and framing have originated in cognitive psychology with the latter having roots in sociology as well 
(Higgins, 1996, Tversky \& Kahnemann, 1973, Goffman, 1974). Framing per se will not be considered here, but the extent to which framing theorists analyzed priming in media effects their views will be used. For example, Scheufele \& Tewksbury (2007) linked agenda setting and priming in the following way: "By making some issues more salient in people's mind (agenda setting), mass media can also shape the considerations that people take into account when making judgments about political candidates or issues (priming)." (p.9). The media agenda as the independent variable affects the audience agenda as the dependent variable, and we have agenda setting effects. In regards to priming, the audience agenda becomes the independent variable making priming effects the dependent variable (Scheufele, 2000). Multiple definitions vary a lot and name priming either a process or an effect. Specifically, following Higgins (1996), some scholars (Price, V., \& Tewksbury, D., 1997; Scheufele \& Tewksbury, 2007) reduce priming to increased accessibility.

However, priming models based on accessibility only overlook factors that are in the heart of mass communication processes. For example, Carpentier (2014) put it, "Priming ignores the importance of information source in its theorization." (p.6). To sort out what clarifications or modifications priming definitions in agenda setting may need , the most popular definition: "priming refers to changes in the standards that people use to make political evaluations" (Iyengar \& Kinder, 1987, p. 63). The authors then claimed that they developed and tested a theory of priming. They in fact tested a priming hypothesis applied to mass communication and demonstrated priming effects, but to say that they developed a theory is an overshoot. The section "A theory of priming" is two-pages long, and it discusses two key elements: accessibility and standards. The standards of evaluations, one of the key concepts in their definition was not defined, but they singled out the impressions of audience members as organized around central themes which become central standards. The standards were limited to presidents' evaluations only, which raises the question whether standards may take any different form under other circumstances. The authors also stated that television news coverage determines the standards citizens use to judge news characters, and that the frequency of primes usage leads to stronger priming effects (p. 65). It is not about criticizing the authors. After all, their book News That Matters made a significant and lasting contribution to the fields of media effects. The point is that their theorizing of priming was based on the existed level of knowledge and was used with a particular area of application in mind. Their work relied on a borrowed definition of priming from psychology. The authors put forward a working hypothesis adjusted to the realities of mass communication and put to the experimental test. They coped with the task perfectly: their working model of priming demonstrated that priming exists in the mass communication that it is related to agenda setting, but we need to clarify and further theoretically develop what leads to these effects- priming itself. Twenty five years later, Iyengar and Kinder (2010) acknowledged that they showed how priming applies to political communication, but they also hailed further developments focusing on possibilities of more deliberative, conscious components of priming and noted psychological explorations in priming as a media effect.

It is not that there were no efforts to better explicate priming as an extension of agenda setting. For example, Lee (2010) connected Iyengar and Kinder (1987) to McCombs' (2004) typology of agenda setting and placed priming in the evaluative dimension. According to McCombs, one of the levels of agenda setting affects the direction of opinions people form, and based on Iyengar and Kinder's work assign the role of "opinions organizer" to priming. Priming in such a view is triggered by media highlighting certain aspects of a message and determines the direction of opinions. Need for information becomes a psychological mechanism that can serve as a mediator in the whole process (McCombs, M., \& Stroud, N., 2014). Despite certain heuristic value of the "opinions organizer" metaphor, it still lacks definitional preciseness, and this formula does not pin down exactly how the process of opinion organization works.

Some definitions call priming an impact of agenda setting on evaluations (Kim, Han, Choy, Kim, 2012). The authors also specify that priming works as a dimension of evaluation without a detailed description of this dimension, but they state that priming is expressed in assigning more weight to certain aspects of media messages by the audience. The latter may indicate the relative strength of evaluation without dealing with the direction of it. This study also cited Iyengar and Kinder's definition of priming without further elaborations.

There has been a substantial progress in agenda setting on the issue of accessibility in priming.

As pointed earlier, some scholars (Price, V., \& Tewksbury, D., 1997; Scheufele \& Tewksbury, 2007) limited priming to the increased accessibility, trivializing, and possibly misrepresenting what happens during the agenda-setting process. In fact, Miller and Krosnick (2000) stated that accessibility does not determine the weight people assign to issues and evaluations. There has to be something else aside from accessibility that includes a certain level of conscious effort on behalf of individuals. Roessler and Eichhorn (1999) argued that accessibility has more in common with the awareness of an issue, which can be seen as a prerequisite for the following agenda-setting effects. Furthermore, Bulkow, Urban, and Schweiger (2012) pointed at the fact that agenda setting happens both when people use deliberate and automatic processing of media information. Using deliberate information processing definitely cannot rely only on the accessibility of issues. Even using less conscious, more peripheral route (Petty \& Cacioppo, 1986) does not imply that 
some conscious cognitive efforts are excluded from the process. More important for evaluations than accessibility may become relevance of the issue: "whether agenda-setting is carried out more automatically or more deliberately depends on the degree to which an issue is relevant to a person's life." (Bulkow, Urban, and Schweiger, 2012, p.5)

Priming models based on accessibility only overlook factors that are in the heart of mass communication processes. As Carpentier (2014) put it, "Priming ignores the importance of information source in its theorization." (p.535). For priming to work, accessibility may only serve as a factor making assigning importance to an issue or an object easier. Assigning importance require a certain level of deliberation, because individuals make inferences about what is important (Miller, 2007)

Another way of looking at the priming mechanism is to implicate selective attention in this process (McCombs, 2013). According to the late-selection model of attention (Luck, 2016), irrelevant information could be suppressed at any stage of information processing. Even when some information is made accessible automatically, deliberate attention to its whole context is needed to include this information into later evaluations and opinions. In other words, priming in agenda includes a broader information processing and relevance of a media message as well as the importance of the context of a media message to be evaluated. This short review of priming as it applies to agenda setting demonstrates that some gaps and inconsistencies in its interpretation exist and they require revisiting its definitional and conceptual aspects. Enough information accumulated to definitively answer the questions:

Is priming a result of an automatic process? And is the mechanism of priming limited by accessibility only?

Even a few examples of priming explication in agenda setting attest to its definitional complexity.

\section{Revisiting Priming}

Priming has evolved into a concept with a high heuristic value and broad applicability in different areas of knowledge. This concept also has become an indispensable part of the agenda setting approach. Over the years, priming was shown to lead to undeniable effects and certain efforts were made to clarify this concept, and to show how it works (Carpentier, 2014; Kim, Han, Choi, \& Kim, 2012; Lee, 2010; McCombs, 2013, to name a few). Despite this progress, priming was mostly analyzed as an extension of agenda setting, not as an independent model. Such practice resulted in explicating something not conceptually clear, but what still leads to certain definite and well documented effects. Priming was a borrowed concept from psychology. Because of that there is a need to account for advances in its study in psychology and media, and continue to work on exploring how specifically it applies to agenda setting. What follows is a sketch of how priming could be revisited for this purpose.

As psychological studies of priming demonstrated, relevance and judged usability complement the process of priming. A media message as a trigger may have a different impact on the audience member depending on whether people see such a message important and how motivated they are to process it. No matter how frequent or strong a media prime is intended to be, its effects will vary depending on whether the context of the prime does not allow to apply it or its application is deemed as a stretch. Mental models developed in media priming as the insight into the process of not only accessing, but also creating mental representations of the prime and its context and making inferences prior to evaluations of the concepts of what media primed.

As we have seen, to prime does not equate to making accessible through concept activation only. Described as automatic activation, priming starts from a deliberate and targeted exposure. In agenda setting, for example, it is the order and amount of coverage dedicated to specific issues. Even if the media aim at teaching the audience something, the media do not aim at the audience to be aware of learning. Unlike the case of persuasive communication, the key message of media as described by agenda setting is not "accept our stance", but "stay with us". However, as we stay, we by the same token learn, and as we learn we re-evaluate. Agenda setting makes certain issues prominent and priming connects this prominence with evaluation. Audiences have little control over which media message they will be exposed to, but they control what they know about the issues and how they evaluate them. Media messages do not only activate stored knowledge, but also provide certain new information that is scanned and incorporated into the existing mental model related to this knowledge. Activating the constructs related to the message focal point may evoke the constructs related to primes, but not intended to be primed. In this more complicated picture, priming looks more like a product of confluence of media exposure, automated activation of and the increased accessibility to the constructs. Priming is often complemented by more deliberate inferences about activated information. Some degree of deliberate processing is needed on behalf of audiences to scan this information and incorporate it into a mental model based on relevance and importance of this information. Starting as an automated process, priming evokes constructs that are activated with mental representation associated with them, and the sorting of how relevant and applicable these associations are takes place. This sorting prepares primed concepts for subsequent evaluations. These evaluations become boundaries for priming, the point where priming ends. 
Based on the above discussion, priming as a media effect phenomenon could be preliminarily defined as a change in a direction of evaluation or opinion about an object or an issue invoked by a certain message through activating a related concept to such an object or an issue. Priming may take place through making a related concept to an opinion accessible and by active scanning of a broader context surrounding an evaluation or opinion and a concept made accessible.

The notion of 'standard' is not included in this definition because it may need to be defined more clearly itself. Current literature does not offer persuasive examples of what specific standards are and how they change as a consequence of priming.

The offered view of priming is more extended than its classic definitions limited by activation and accessibility, but it has a clear entry point- starting activation of the constructs after being exposed to media message, and a clear exit point - activation and re-evaluation of strength and direction of existing evaluations and opinions beyond which a deliberate process of opinion modification and reinforcement or change takes place.

There is a difference between conceptualizing of priming in psychology and agenda setting that will exist in the future. Agenda setting may not need to embrace all the intricacies of memory activation and memory retrieval, for example, but the idea of consequential and parallel retrievals (Wyer, 2007) may help in determining how deliberate or autonomous the priming process in assessing media messages is. Or it could be too technical to describe the stages at which such heuristics as accessibility, availability and judged usability enter mental representations and spill over into evaluations. However, to determine what media frames or message attributes lead to more automatic or more deliberate retrieval of concepts for subsequent judgments could be beneficial for agenda setting (Ottati, Wilson, Lambert, 2016).

Priming is an effective explanatory tool, and it has a heuristic value, but to generate further progress in increasing our knowledge about psychological mechanisms of media influence, its theoretical bases and practical applications should be regularly revisited and re-evaluated. This article is not aimed at offering complete and exhaustive theoretical overview of the issues related to priming. Its novelty and importance is in treating priming not as a secondary extension accompanying agenda setting, but as a concept that deserves serious theoretical exploration. The article is an invitation to further explore what are specific features that make priming so important and indispensable partner of agenda setting.

\section{References}

Appel, M. (2011). A story about a stupid person can make you act stupid (or smart): Behavioral assimilation (and contrast) as narrative impact. Media Psychology, 14, 144-167. https://doi.org/10.1080/15213269.2011.573461

Arendt, F. (2015). Toward a dose-response account of media priming. Communication Research, 42(8), 1089-1115. https://doi.org/10.1177/0093650213482970

Bargh, J. A. (2006). What have we been priming all these years? On the development, mechanisms, and ecology of nonconscious social behavior. European Journal of Social Psychology, 36(2), 147-168. https://doi.org/10.1002/ejsp.336

Bargh, J. A. (2013). Social psychology and the unconscious: The automaticity of higher mental processes. Psychology Press.

Biernat, M., \& Eidelman, S. (2007). Standards. In A. W. Kruglanski \& E. T. Higgins (Eds.), Social psychology: Handbook of basic principles (2nd ed., pp. 308-333). New York, NY: Guilford Press.

Blumler, J. G. (2015). Core theories of political communication: Foundational and freshly minted. Communication Theory, 25(4), 426-438. https://doi.org/10.1111/comt.12077

Brewer, P. R., Graf, J., \& Willnat, L. (2003). Priming or framing: media influence on attitudes toward foreign countries. The International Journal for Communication Studies, 65, 493-508. https://doi.org/10.1177/0016549203065006005

Bulkow, K., Urban, J., \& Schweiger, W. (2012). The Duality of Agenda-Setting: The Role of Information Processing. International Journal of Public Opinion Research.

Cacciatore, M. A., Scheufele, D. A., \& Iyengar, S. (2016). The end of framing as we know it and the future of media effects. Mass Communication and Society, 19(1), 7-23. https://doi.org/10.1080/15205436.2015.1068811

Carpentier, F. R. D. (2014). Agenda setting and priming effects based on information presentation: Revisiting accessibility as a mechanism explaining agenda setting and priming. Mass Communication \& Society, 17(4), 531-552. https://doi.org/10.1080/15205436.2013.816744

Doyen, S., Klein, O., Simons, D. J., \& Cleeremans, A. (2014). On the other side of the mirror: Priming in cognitive and social psychology. Social cognition, 32(Supplement), 12. https://doi.org/10.1521/soco.2014.32.supp.12 
Förster, J., \& Liberman, N. (2007). Knowledge activation. In A. W. Kruglanski \& E. T. Higgins (Eds.), Social psychology: Handbook of basic principles (2nd ed., pp. 201-231). New York, NY: Guilford Press.

Garnham, A., \& Oakhill, J. (2013). Mental models in cognitive science: Essays in honour of Phil Johnson-Laird. Psychology Press.

Ghanem, S. I. (1997). Filling in the tapestry: The second level of agenda setting. In M. E. McCombs, ed., D. Shaw, ed. \& D. Weaver (Eds.), Communication and democracy (pp. 309-330) . Mahwah, NJ: Lawrence Erlbaum

Ghanem, S., McCombs, M., \& Chernov, G. (2009). Agenda setting and framing. In William Eadie, (Ed.) $21^{\text {st }}$ Century Communication. Thousand Oaks, CA: Sage. https://doi.org/10.4135/9781412964005.n57

Goffman, E. (1974). Frame analysis: An essay on the organization of experience. Harvard University Press.

Hart, A., \& Middleton, J. A. (2014). Priming under fire: Reverse causality and the classic media priming hypothesis. The Journal of Politics, 76(02), 581-592. https://doi.org/10.1017/S0022381613001539

Higgins, E. T. (1990). Personality, social psychology, and person-situation relations: Standards and knowledge activation as a common language. In L. A. Pervin (Ed.), Handbook of personality (pp. 301- 338). New York: Guilford Press

Higgins, E. T. (1996). Knowledge activation: Accessibility, applicability and salience. In E. T. Higgins \& A. W. Kruglanski (Eds.), Social psychology: Handbook of basic principles (pp. 133-168). New York, NY: Guilford.

Higgins, E. T., \& Eitam, B. (2014). Priming...Shmiming: It's About Knowing When and Why Stimulated Memory Representations Become Active. Social Cognition: 32, Understanding Priming Effects in Social Psychology, 225-242. https://doi.org/10.1521/soco.2014.32.supp.225

Higgins, E. T., King, G. A., \& Mavin, G. H. (1982). Individual construct accessibility and subjective impressions and recall. Journal of Personality and Social Psychology, 43(1), 35. https://doi.org/10.1037/0022-3514.43.1.35

Iyengar, S., \& Kinder, D. R. (1987). News that matters: Television and American opinion. Chicago: University of Chicago Press. https://doi.org/10.7208/chicago/9780226388601.001.0001

Iyengar, S., \& Kinder, D. R. (2010). News that matters: Television and American opinion. Chicago: University of Chicago Press. Updated Ed.

Jacobson, A. J. (2013). Aristotelian Representations II. In Keeping the World in Mind (pp. 45-56). Palgrave Macmillan UK. https://doi.org/10.1057/9781137315588_4

Johnson-Laird, P. (1989). Mental Models. In M. Posner (ed.): Foundations of Cognitive Science. Cambridge MA, MIT Press

Kim, S. H., Han, M., Choi, D. H., \& Kim, J. (2012). Attribute agenda setting, priming and the media's influence on how to think about a controversial issue. International Communication Gazette, 74(1), 43-59. https://doi.org/10.1177/1748048511426991

Lang, A., \& Ewoldsen, D. (2010). Beyond effects: Conceptualizing communication as dynamic, complex, nonlinear, and fundamental. In S. Allan (Ed.), Rethinking communication. Keywords in communication research (pp. 109-120). Cresskill, NJ: Hampton Press

Lee, G. (2010). Who let priming out? Analysis of first-and second-level agenda setting effects on priming. International Communication Gazette, 72(8), 759-776. https://doi.org/10.1177/1748048510380814

Lenz, G. (2009). Learning and Opinion Change, Not Priming: Reconsidering the Evidence for the Priming Hypothesis. American Journal of Political Science, 53(4), 821-837. https://doi.org/10.1111/j.1540-5907.2009.00403.x

Lenz, G. (2012). Follow the Leader? Chicago: University of Chicago Press. https://doi.org/10.7208/chicago/9780226472157.001.0001

Luck, S. (2016). Neurophysiology of Selective attention (p. 257-296) in Pashler, H. (Ed.). (2016). Attention. Psychology Press.

Markman, K. D., \& McMullen, M. N. (2003). A reflection and evaluation model of comparative thinking. Personality and Social Psychology Review, 7, 244-267. https://doi.org/10.1207/S15327957PSPR0703_04

McCombs, M. (2004). Setting the Agenda: The Mass Media and Public Opinion. Cambridge: Polity Press.

McCombs, M. (2013). Setting the agenda: The mass media and public opinion. John Wiley \& Sons.

McCombs, M., \& Stroud, N. J. (2014). Psychology of Agenda-Setting Effects. Mapping the Paths of Information Processing. Review of Communication Research, 2(1), 68-93. 
Miller, J. M. (2007). Examining the mediators of agenda setting: A new experimental paradigm reveals the role of emotions. Political Psychology, 28, 689-717. https://doi.org/10.1111/j.1467-9221.2007.00600.x

Miller, J. M., \& Krosnick, J. A. (2000). News media impact on the ingredients of presidential evaluations: Politically knowledgeable citizens are guided by a trusted source. American Journal of Political Science, 44(2), 301-315. https://doi.org/10.2307/2669312

Molden, D. C. (2014). Understanding priming effects in social psychology: What is "social priming" and how does it occur? Understanding Priming Effects in Social Psychology, 3.

Ottati, V., Wilson, C., \& Lambert, A. (2016). Accessibility, priming, and political judgment. Current Opinion in Psychology, 12, 1-5. https://doi.org/10.1016/j.copsyc.2016.04.010

Paivio, A. (1986). Mental representations: A dual coding approach. Oxford University Press.

Petty, R. E., \& Cacioppo, J. T. (1986). The elaboration likelihood model of persuasion. In Communication and persuasion (pp. 1-24). Springer New York.

Potter, W. J. (2014). Patterns in the Use of Theory in Media Effects Research. The Handbook of Media and Mass Communication Theory, 95-114. https://doi.org/10.1002/9781118591178.ch6

Price, V., \& Tewksbury, D. (1997). News values and public opinion: A theoretical account of media priming and framing. In G. A. Barnett \& F. J. Boster (Eds.), Progress in communication sciences (pp. 173-212). Greenwich, CT: Ablex.

Roessler, P., \& Eichhorn, W. (1999). Agenda-setting. In H.-B. Brosius \& C. Holtz-Bacha (Eds.), German communication yearbook, (Vol. 1, pp. 277-304). Cresskill, NJ: Hampton Press.

Roskos-Ewoldsen D. R., \& Roskos-Ewoldsen, B. (2009). 'Current Research in Media Priming', [in:] NABI, R. L. and OLIVER, M. B. (eds), The SAGE Handbook of Media Processes and Effects, Los Angeles: Sage, 177-192.

Roskos-Ewoldsen, D. R., \& Roskos-Ewoldsen, B (2009). Current research in media priming. In Nabi, Robin L., and Mary Beth Oliver (eds.), The SAGE Handbook of Media Processes and Effects, Los Angeles, CA: Sage

Roskos-Ewoldsen, D. R., Roskos-Ewoldsen, B., \& Carpentier. F. D. (2009). Media priming: An updated synthesis. In J. Bryant and M. B. Oliver (Eds.), Media effects: Advances in theory and research, (pp. 74-93). New York: Routledge

Scheufele, D. A. (2000). Agenda-setting, priming, and framing revisited: Another look at cognitive effects of political communication. Mass Communication \& Society, 3(2-3), 297-316. https://doi.org/10.1207/S15327825MCS0323_07

Scheufele, D. A., \& Tewksbury, D. (2007). Framing, agenda setting, and priming: The evolution of three media effects

\section{Copyrights}

Copyright for this article is retained by the author(s), with first publication rights granted to the journal.

This is an open-access article distributed under the terms and conditions of the Creative Commons Attribution license which permits unrestricted use, distribution, and reproduction in any medium, provided the original work is properly cited. 